\title{
Erratum to: Warmed and humidified carbon dioxide for abdominal laparoscopic surgery: meta-analysis of the current literature
}

\author{
David Balayssac $^{1,2,3} \cdot$ Bruno Pereira $^{1} \cdot$ Jean$^{-E t i e n n e ~ B a z i n}{ }^{1,2,4} \cdot$ Bertrand Le Roy $^{5}$ • \\ Denis Pezet $^{1,2,5} \cdot$ Johan Gagnière ${ }^{5}$
}

Published online: 29 December 2016

(C) Springer Science+Business Media New York 2016

\section{Erratum to: Surg Endosc \\ DOI 10.1007/s00464-016-4866-1}

Some information must be provided to ameliorate the comprehension of the forest plot. It is important to note that these modifications do not change the conclusion of the meta-analysis.

The forest plots presented the standard difference in means between "standard" and "humidified and heated $\mathrm{CO}_{2}$ ". These forest plots were made in favour of humidified and heated $\mathrm{CO}_{2}$. They presented the significance and the difference direction of the analysed factor (between "standard" and "humidified and heated $\mathrm{CO}_{2}$ "). More precisely, if the analysis plot was on the left and different from 0 , the difference between the two procedures was significant and the score of the outcome was lower for "warmed and humidified $\mathrm{CO}_{2}$ " than for "standard," for example Fig. 2a: pain scores were lower with humidified and heated $\mathrm{CO}_{2}$. And inversely, if the analysis plot was on the right and different from 0 , the difference was in favour of the "warmed and humidified $\mathrm{CO}_{2}$ " and the score of the outcome was higher for "warmed and humidified $\mathrm{CO}_{2}$ " than for "standard," for example Fig. 4a: core temperature was higher for "warmed and humidified $\mathrm{CO}_{2}$ " than for "standard."

In consequence, the information top left for each forest plot: "standard" and "warmed and humidified," gives a false interpretation and has been removed of forest plots.

The online version of the original article can be found under doi:10.1007/s00464-016-4866-1.

David Balayssac

dbalayssac@chu-clermontferrand.fr

1 Délégation à la Recherche Clinique et à l'Innovation, CHU de Clermont-Ferrand, Villa annexe IFSI, 58, rue Montalembert, 63003 Clermont-Ferrand Cedex, France

2 Faculté de Médecine et de Pharmacie, Clermont Université, 63001 Clermont-Ferrand, France

3 INSERM, U1107, 63000 Clermont-Ferrand, France

4 Anesthésie Réanimation, CHU de Clermont-Ferrand, 63058 Clermont-Ferrand, France

5 Chirurgie Digestive, CHU de Clermont-Ferrand, 63058 Clermont-Ferrand, France 


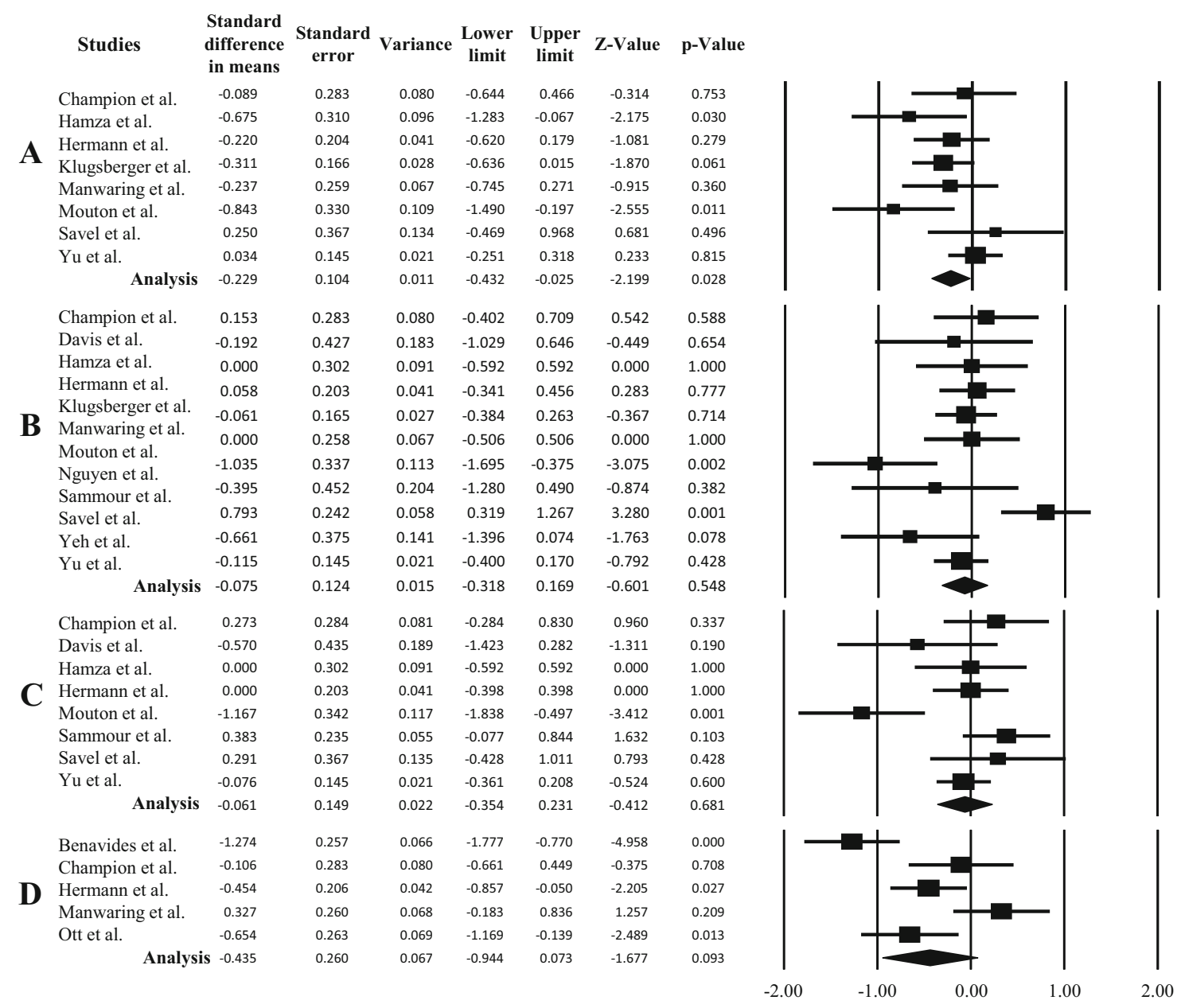

Fig. 2 Forest plot comparison for pain scores between standard versus warmed and humidified gas for laparoscopy. a Immediate post procedure, b post procedure day 1 , c post procedure day 2 and d shoulder pain. The forest plot is made in favour of humidified and heated $\mathrm{CO}_{2}$ and presents the significance and the difference direction of the analysed factor 


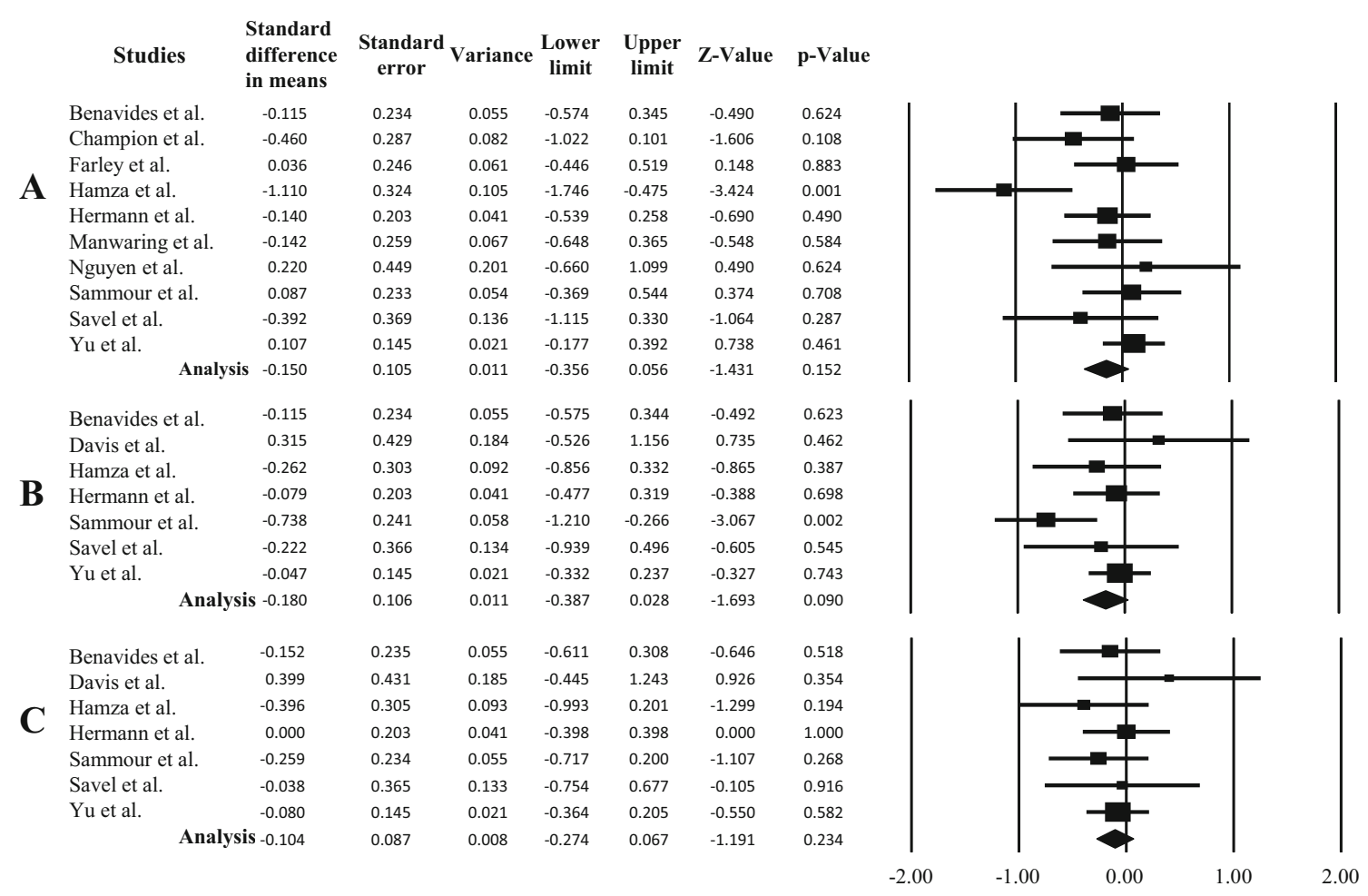

Fig. 3 Forest plot comparison for morphine equivalent daily dose scores between standard versus warmed and humidified gas for laparoscopy. a Immediate post procedure, b post procedure day 1 and

c post procedure day 2. The forest plot is made in favour of humidified and heated $\mathrm{CO}_{2}$ and presents the significance and the difference direction of the analysed factor

\begin{tabular}{lccccc} 
Studies & $\begin{array}{c}\text { Standard } \\
\text { difference } \\
\text { in means }\end{array}$ & $\begin{array}{c}\text { Standard } \\
\text { error }\end{array}$ & Variance & $\begin{array}{c}\text { Lower } \\
\text { limit }\end{array}$ & $\begin{array}{c}\text { Upp } \\
\text { limi }\end{array}$ \\
& 0.000 & 0.246 & 0.061 & -0.483 & 0.483 \\
Farley et al. & 0.545 & 0.168 & 0.028 & 0.216 & 0.875 \\
Klugsberger et al. & 0.234 & 0.259 & 0.067 & -0.274 & 0.742 \\
Manwaring et al. & 0.234 & 0.233 & 0.054 & -0.123 & 0.790 \\
Sammour et al. & 0.333 & 0.145 & 0.021 & -0.131 & 0.438 \\
Yu et al. & 0.153 & 0.095 & 0.009 & 0.086 & 0.458 \\
\multicolumn{1}{c}{ Analysis } & 0.272 & & & & \\
Champion et al. & -0.221 & 0.284 & 0.080 & -0.777 & 0.335 \\
Farley et al. & -0.167 & 0.247 & 0.061 & -0.650 & 0.317 \\
Hamza et al. & 4.745 & 0.589 & 0.347 & 3.590 & 5.89 \\
Kissler et al. & -0.571 & 0.341 & 0.116 & -1.239 & 0.096 \\
Manwaring et al. & 0.166 & 0.259 & 0.067 & -0.340 & 0.673 \\
Nguyen et al. & -0.555 & 0.456 & 0.208 & -1.448 & 0.339 \\
Savel et al. & 0.905 & 0.383 & 0.147 & 0.154 & 1.657 \\
Yu et al. & 0.143 & 0.145 & 0.021 & -0.142 & 0.428 \\
\multicolumn{1}{c}{ Analysis } & 0.440 & 0.335 & 0.112 & -0.216 & 1.096 \\
& & & & &
\end{tabular}

Fig. 4 Forest plot comparison for body core temperature between standard versus warmed and humidified gas for laparoscopy. a Per procedure and $\mathbf{b}$ post procedure. The forest plot is made in favour of

\section{Z-Value p-Value}

$\begin{array}{rl}0.000 & 1.000 \\ 3.243 & 0.001 \\ 0.903 & 0.366 \\ 1.431 & 0.152 \\ 1.056 & 0.291 \\ 2.864 & 0.004 \\ -0.778 & 0.436 \\ -0.676 & 0.499 \\ 8.056 & 0.000 \\ -1.678 & 0.093 \\ 0.644 & 0.520 \\ -1.217 & 0.224 \\ 2.361 & 0.018 \\ 0.983 & 0.325 \\ 1.314 & 0.189\end{array}$
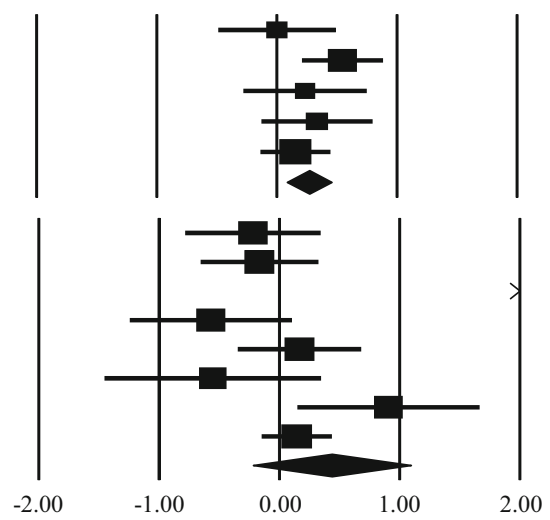

humidified and heated $\mathrm{CO}_{2}$ and presents the significance and the difference direction of the analysed factor 


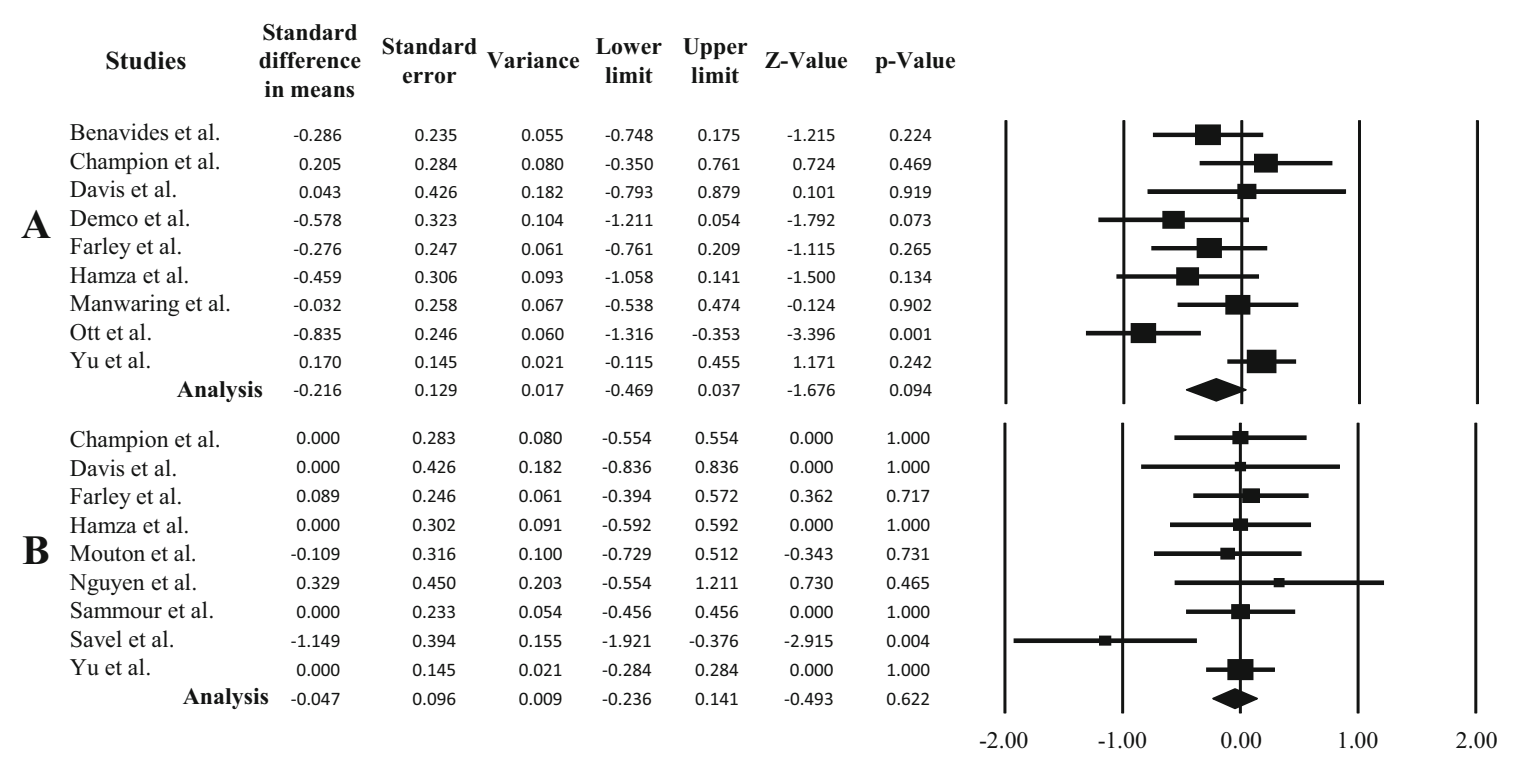

Fig. 5 Forest plot comparison for recovery room (a) and hospitalisation (b) duration between standard versus warmed and humidified gas for laparoscopy. The forest plot is made in favour of humidified and heated $\mathrm{CO}_{2}$ and presents the significance and the difference direction of the analysed factor

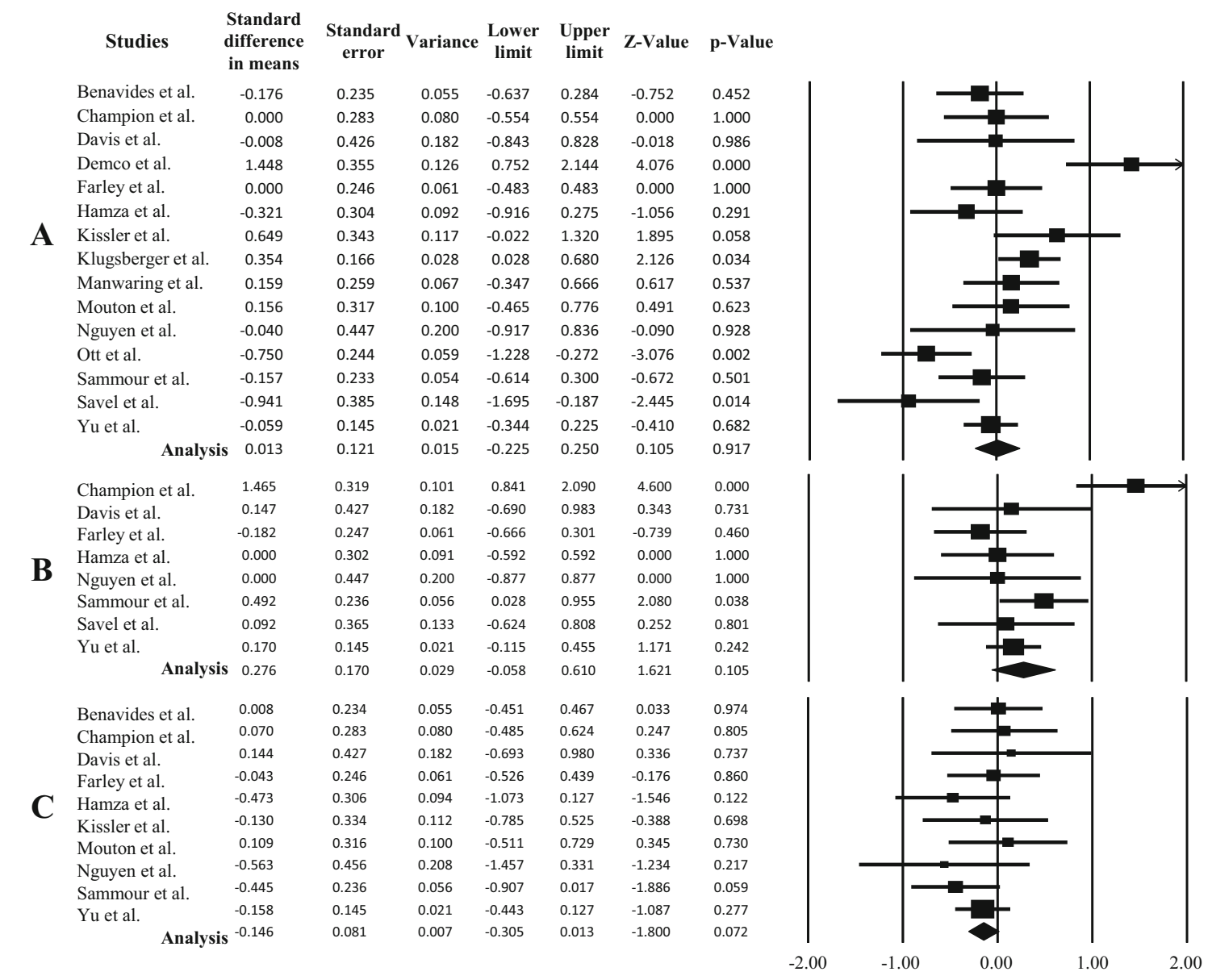

Fig. 6 Forest plot comparison for procedure duration (a), lens fogging (b) and gas volume (c) duration between standard versus warmed and humidified gas for laparoscopy. The forest plot is made in favour of humidified and heated $\mathrm{CO}_{2}$ and presents the significance and the difference direction of the analysed factor 